\title{
Bayesian Neural Network Analysis of Fatigue Crack Growth Rate in Nickel Base Superalloys
}

\author{
Hidetoshi FUJII, D. J. C. MACKAY ${ }^{1)}$ and H. K. D. H. BHADESHIA ${ }^{1)}$ \\ Department of Materials Science and Metallurgy, University of Cambridge, Pembroke Street, Cambridge CB2 3OZ, UK. \\ 1) Darwin College, Mathematics and Physical Sciences Group, Silver Street, Cambridge CB3 9EU, UK.
}

(Received on May 13, 1996; accepted in final form on September 9, 1996)

\begin{abstract}
The fatigue crack growth rate of nickel base superalloys has been modelled using a neural network model within a Bayesian framework. A 'committee' model was also introduced to increase the accuracy of the predictions. The rate was modelled as a function of some 51 variables, including stress intensity range $\Delta K$, $\log \Delta K$, chemical composition, temperature, grain size, heat treatment, frequency, load waveform, atmosphere, $R$-ratio, the distinction between short crack growth and long crack growth, sample thickness and yield strength. The Bayesian method puts error bars on the predicted value of the rate and allows the significance of each individual factor to be estimated. In addition, it was possible to estimate the isolated effect of particular variables such as the grain size, which cannot in practice be varied independently. This demonstrates the ability of the method to investigate new phenomena in cases where the information cannot be accessed experimentally.
\end{abstract}

KEY WORDS: fatigue cracks; neural network; nickel-base superalloys; modelling.

\section{Introduction}

Superalloys have been used in aeroengine gas turbines for about 50 years. Their weight percentage in engines has increased over the years to $30 \%$. The safe service lives of these components are increasingly becoming fatigue limited due to the high operating stress. ${ }^{1\}}$ Indeed, low cycle fatigue performance had become the life limiting factor in over $75 \%$ of major structural components of advanced engines by $1975 .^{2)}$ Fatigue in turbine discs arises from the variations in both thermal and mechanical stress during the flight. A typical loading cycle comprises starting up, takeoff and climb, cruising, landing and shut-down. The highest stresses are experienced in the bore of the disc early in the flight cycle, generally while it is in the lower temperature range $200-300^{\circ} \mathrm{C}$. Stress in the rim region is lower, but at a higher temperature, $500-600^{\circ} \mathrm{C}^{3)}$

Thus, the requirements for fatigue crack propagation are dependent on the environment where the material is used. Full quantification of fatigue crack growth rate is essential in both life prediction and in the development of new materials. However, the fatigue propagation is affected by many factors including chemical composition, grain size, heat treatment, temperature, atmosphere, $R$-ratio and frequency. Accordingly, the modelling of fatigue has to cover a wide range of conditions, and it is not easy to predict the fatigue crack growth rate of an unknown material. In this study, in view of the complexity of the phenomena, neural network models were applied in place of the usual regression analysis or physical models. Neural networks are capable of realising a variety of non-linear relationships of considerable complexity. Once a network has been trained, the estimation of the outputs is very rapid.

A difficulty with neural network models is that an over-flexible network can 'discover' false structure in data, a behaviour known as 'overfitting'. We have used a Bayesian framework ${ }^{4}$ in order to control this problem. This mitigates against excessive complexity and permits the calculation of error bars, indicative of the reliability of the prediction. ${ }^{5)}$ In addition, in this study a committee model is introduced to make predictions more accurate. These approaches, combined with metallurgical theory have been used here to model the fatigue crack growth rate in nickel base alloys.

\section{Neural Network Framework}

Figure 1 shows the structure of the neural network used in our model. Factors such as chemical composition, grain size, heat treatment and temperature are input from the left hand side. To predict the output, that is, the logarithm of the fatigue crack growth rate, hidden units were used between the input and the outputs so that more complex relationships could be expressed. The

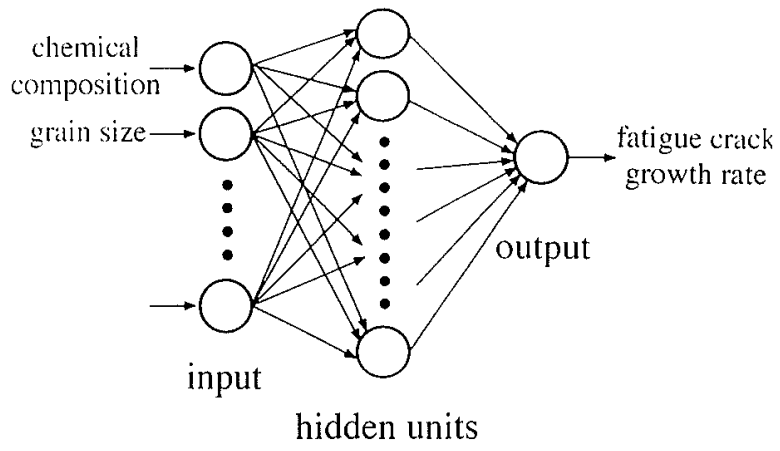

Fig. 1. Neural network model used in this study. 
transfer function relating the inputs to the $i$ th hidden units is given by

$$
h_{i}=\tanh \left(\sum_{j} w_{i j}^{(1)} x_{j}+\theta_{i}^{(1)}\right)
$$

The relationship between the hidden units and the output is a linear:

$$
y=\sum_{i} w_{i}^{(2)} h_{i}+\theta^{(2)}
$$

The coefficients $w$ and biases $\theta$ of these equations are determined in a such way as to minimize the energy function, as explained later. Becuase the hyperbolic function is a non-linear function, a non-linear relationship can be predicted in this model.

\section{The Data Base}

The data base consists of 1894 combinations of fatigue crack growth and 51 inputs including the stress intensity factor range $\Delta K$, chemical composition, temperature, grain size, the condition of heat treatment, frequency, loading condition, atmosphere, $R$-ratio, load waveform, sample thickness and yield strength. All these data are from the published literature. ${ }^{3,6-38)}$ Table 1 shows the details of the data used for the modelling.

Many of the nickel base superalloys were given three steps of heat treatment. Each heat treatment was specified as a combination of temperature, time and cooling rate. When fewer than 3 steps of heat treatment were carried out, the temperature, the duration and cooling rate of the remaining steps were set to zero. The cooling rates were assigned relative magnitudes as follows ${ }^{39)}$ :

$$
\begin{aligned}
& \text { Water Quench : Oil Quench : Air Cooling: } \\
& \qquad \text { Furnace Cooling }=60: 30: 10: 1
\end{aligned}
$$

The shape of load waveform was defined as shown in Fig. 2. A sinusoidal waveform was defined as 0 and a triangular waveform as 1 . The 'loading time', during which the maximum load is being applied, and the 'unloading time', during which the minimum load is applied, were also selected as input factors so that the triangular load waveform covers also trapezium or square shape waveforms. The grain size was defined by three factors: two of the three are the maximum grain size and the minimum grain size in the distribution. The microstructure is sometimes inhomogeneous, containing some regions with a fine grain size and others where the size is coarse. The difference between the mean grain size in these two regions in sometimes quoted and is used here as an input. The data for short-crack growth were also included. Short-crack growth was defined as 0 and long-crack growth as $1 . \log \Delta K$ is included as an input factor because it has a metallurgical meaning and hence helps to find the optimum relationship between the input and the output.

\section{The Analysis}

Both the input and output variables were first normalized within the range \pm 0.5 as follows:

$$
x_{\mathrm{N}}=\frac{x-x_{\min }}{x_{\max }-x_{\min }}-0.5
$$

\begin{tabular}{|c|c|c|c|}
\hline Variable & Range & Mean & Standard Deviation \\
\hline $\mathrm{da} / \mathrm{dN}, \mu \mathrm{m}$ & $1.0 \times 10^{-8}-0.646$ & $\cdots$ & $\cdots$ \\
\hline $\log \mathrm{da} / \mathrm{dN}, \mu \mathrm{m}$ & $-8--0.1898$ & .. & $\cdots$ \\
\hline$\Delta \mathrm{K}, \mathrm{MPa} \mathrm{m}^{-1 / 2}$ & $4.03-246$ & 27.16 & 22.47 \\
\hline $\log \Delta \mathrm{K}, \mathrm{MPa} \mathrm{m}^{-1 / 2}$ & $0.605-2.39$ & 1.316 & 0.3167 \\
\hline Temperature, $\mathrm{K}$ & $293-1123$ & 660.3 & 304.5 \\
\hline Minimum grain size, $\mu \mathrm{m}$ & $7-5000$ & 295.8 & 1024 \\
\hline Maximum grain size. $\mu \mathrm{m}$ & $7-5000$ & 313.2 & 1022 \\
\hline $\begin{array}{l}\text { Difference in grain size between } \\
\text { major phase and minor phase }\end{array}$ & $-35-0$ & -0.8936 & 5.432 \\
\hline $\begin{array}{l}\text { 1st step Heat Treatment, } \\
\text { Temperature. } \mathrm{K}\end{array}$ & $1116-1578$ & 1321 & 103.0 \\
\hline Duration, hour & $0.5-7$ & 2.602 & 1.685 \\
\hline Cooling rate, $\mathrm{K} / \mathrm{sec}$ & $-15 \cdot 5$ & -5.629 & 3.134 \\
\hline $\begin{array}{l}\text { 2nd step Heat Treatment, } \\
\text { Temperature. } \mathrm{K}\end{array}$ & $0-1413$ & 955.8 & 292.1 \\
\hline Duration, hour & $0-24$ & 12.22 & 9.065 \\
\hline Cooling rate, $\mathrm{K} / \mathrm{sec}$ & $-5-0$ & -3.036 & 2.291 \\
\hline $\begin{array}{c}\text { 3rd step Heat Treatment, } \\
\text { Temperature, } K\end{array}$ & $0-1143$ & 869.3 & 312.0 \\
\hline Duration, hour & $0-24$ & 10.96 & 6.179 \\
\hline Cooling rate, $\mathrm{K} / \mathrm{sec}$ & $-5-0$ & -4.459 & 1.554 \\
\hline Frequency, $\mathrm{Hz}$ & $0.01-100$ & 21.47 & 29.31 \\
\hline Loading Time, s & $0-600$ & 15.27 & 71.96 \\
\hline Unloading Time, s & $0-500$ & 7.439 & 55.14 \\
\hline Load Shape & 0 or 1 & 0.7355 & 0.4412 \\
\hline Atmosphere & $1 \times 10^{-6}-760$ & 691.4 & 217.9 \\
\hline R-ratio & $0.05-0.8$ & 0.171 & 0.2175 \\
\hline Short or long crack growth & 0 or 1 & 0.9161 & 0.2774 \\
\hline Sample thickness, mm & $4.4-25$ & 11.39 & 4.063 \\
\hline Yield Stress, $\mathrm{MPa}$ & $324-1690$ & 911.9 & 242.3 \\
\hline
\end{tabular}

\begin{tabular}{|c|c|c|c|}
\hline Variable & Range & Mean & Standard Deviation \\
\hline $\mathrm{Ni}$, wt $\%$ & 40.73 & 55.34 & 8.234 \\
\hline $\mathrm{Cr}$ & $0.03-19.5$ & 14.89 & 5.127 \\
\hline Co & $0-17$ & 5.982 & 7.552 \\
\hline Mo & $0-6$ & 3.094 & 1.991 \\
\hline $\mathrm{Al}$ & $0.3-5.5$ & 1.926 & 1.732 \\
\hline $\mathrm{Ti}$ & $0.8-3.52$ & 2.107 & 1.098 \\
\hline $\mathrm{Fe}$ & $0-35.56$ & 12.07 & 12.12 \\
\hline $\mathrm{C}$ & $0.007-0.06$ & 0.03865 & 0.01176 \\
\hline B & $0-0.1$ & 0.01418 & 0.02604 \\
\hline $\mathrm{Zr}$ & $0-0.35$ & 0.01907 & 0.04495 \\
\hline $\mathrm{Si}$ & $0-0.31$ & 0.05634 & 0.08841 \\
\hline $\mathrm{Nb}$ & $0-5.35$ & 1.968 & 2.402 \\
\hline $\mathrm{Mn}$ & $0-0.28$ & 0.03728 & 0.07740 \\
\hline $\mathrm{Cu}$ & $0-0.06$ & $4.525 \times 10^{-3}$ & 0.01401 \\
\hline P & $0-0.011$ & $8.551 \times 10^{-4}$ & $2.438 \times 10^{-3}$ \\
\hline $\mathrm{Ca}$ & $0-0.006$ & $2.598 \times 10^{-4}$ & $1.221 \times 10^{-3}$ \\
\hline $\mathrm{Mg}$ & $0-0.002$ & $8.659 \times 10^{-5}$ & $4.071 \times 10^{-4}$ \\
\hline$S$ & $0-0.005$ & $3.350 \times 10^{-4}$ & $1.031 \times 10^{-3}$ \\
\hline Sn & $0-0.0027$ & $1.169 \times 10^{-4}$ & $5,496 \times 10^{-4}$ \\
\hline $\mathrm{Pb}$ & $0-0.00004$ & $1.732 \times 10^{-6}$ & $8.143 \times 10^{-6}$ \\
\hline $\mathrm{Bi}$ & $0-0.0000125$ & $5.412 \times 10^{-7}$ & $2.545 \times 10^{-6}$ \\
\hline $\mathrm{Ag}$ & $0-0.00001$ & $4.329 \times 10^{-7}$ & $2.036 \times 10^{-6}$ \\
\hline W & $0-6.5$ & 0.4628 & 1.539 \\
\hline $\mathrm{Tat}$ & $0-6.5$ & 0.3935 & 1.385 \\
\hline $\mathrm{Hf}$ & $0-0.1$ & $4.488 \times 10^{-3}$ & 0.02071 \\
\hline $\operatorname{Re}$ & $0-3$ & 0.1346 & 0.6213 \\
\hline $\mathrm{Y}_{2} \mathrm{O}_{3}$ & $0-1.1$ & 0.04704 & 0.2226 \\
\hline
\end{tabular}

where $x_{\mathrm{N}}$ is the normalized value of $x, x_{\max }$ is the

Table 1. Input variables for the prediction of fatigue crack growth rate. 
Load Shape $=0$

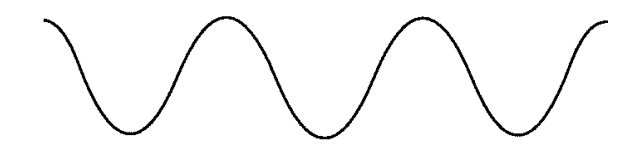

Load Shape $=1$

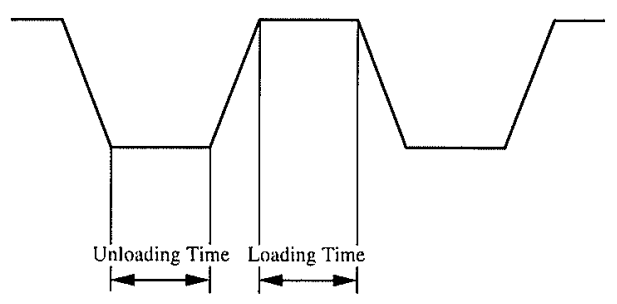

Fig. 2. Definition of load shape.

maximum value and $x_{\min }$ is the minimum value of each variable of the original data. This normalization is not essential to the neural network approach but allows a convenient comparison of the influence of individual input variables on outputs.

Using the normalized data, the coefficients (weights) $w$ and bias $\theta$ were determined in such a way as to minimize the following energy function ${ }^{5)}$.

$$
M(w)=\beta E_{\mathrm{D}}+\sum_{c} \alpha_{c} E_{w(c)}
$$

The minimization was inplemented using a variable metric optimizer. ${ }^{40)}$ The gradient of $M(w)$ was computed using backpropagation algorithm. ${ }^{41)}$ The energy function consists of the error function, $E_{\mathrm{D}}$ and regularization $E_{w}$. The error function is the sum squared error as follws:

$$
E_{\mathrm{D}}(\mathbf{w})=\frac{1}{2} \sum_{m}\left(y\left(\mathbf{x}^{m} ; \mathbf{w}\right)-t^{m}\right)^{2}
$$

where $\left\{x^{m}, t^{m}\right\}$ is the data set. $x^{m}$ represents the inputs and $t^{m}$ the targets. The $m$ is a label of the pair. The error function $E_{\mathrm{D}}$ is smallest when the model fits the data well, i.e., when $y\left(\mathbf{x}^{m} ; \mathbf{w}\right)$ is close to $t^{m}$. The coefficients $w$ and biases $\theta$ shown in Eqs. (1) and (2) make up the parameter vector w. A number of regularizers $E_{w(c)}$ are added to the data error. These regularizers favour functions $y(\mathbf{x} ; \mathbf{w})$ which are smooth functions of $\mathbf{x}$. The simplest regularization method uses a single regularizer $E_{w}=\frac{1}{2} \sum w_{i}^{2}$. Here, however, we have used a slightly more complicated regularization method known as the Automatic relevance determination model. ${ }^{4)}$ Each weight is assigned to a class $c$ depending on which neurons it connects. For each input, all the weights connecting that input to the hidden units are in a single class. The hidden units' biases are in another class, and all the weights from the hidden units to the outputs are in a final class. $E_{w(c)}$ is defined to the sum of the squares of the weights in class $c$. $^{42}$

$$
E_{w(c)}(\mathbf{w})=\frac{1}{2} \sum_{i \in c} w_{i}^{2}
$$

This additional term favours small values of $\mathbf{w}$ and decreases the tendency of a model to 'overfit' noise in the data set. The control parameters $\alpha_{c}$ and $\beta$ together with the number of hidden units determine the complexity

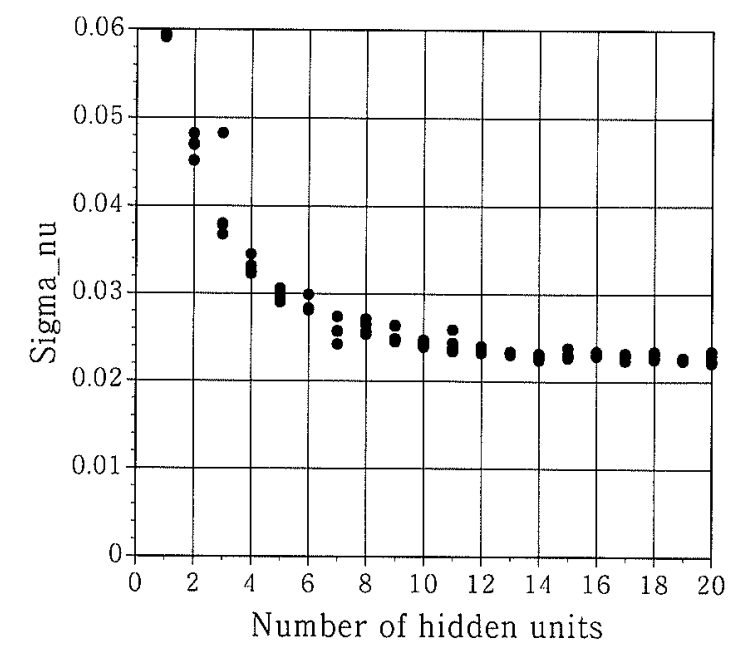

Fig. 3. Variation of $\sigma_{v}$ as a function of number of hidden units.

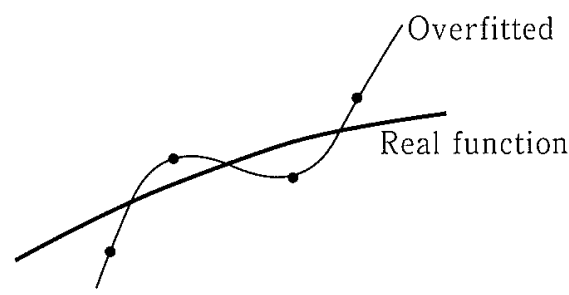

Fig. 4. Overestimation of function.

of the model. These hyperparameters define the assumed Gaussian noise level $\sigma_{v}^{2}=1 / \beta$ and the assumed weight variances $\sigma_{w(c)}^{2}=1 / \alpha_{(c)} \cdot \sigma_{v}$ is the noise level inferred by the model. The parameter $\alpha$ has the effect of encouraging the weights to decay. Therefore, a high value of $\sigma_{w}$ implies that the input parameter concerned explains a relatively large amount of the variation in the output. Thus, $\sigma_{w}$ is regarded as a good expression of the significance of each input though not of the sensitivity of the output to that input. The values of the hyperparameters are inferred from the data using the Bayesian methods of Ref. 42). In this method, the hyperparameters were initialized to values chosen by the operator, and the weights were set to small random initial values (Gaussian with mean 0 and standard deviation 0.3$)$. The objective function $M(\mathbf{w})$ was minimized to a chosen tolerance, then the values of the hyperparameters were updated using a Bayesian approximation given in Ref. 42). The $M(w)$ was minimized again, starting from the final state of the previous optimization, and the hyperparameters were updated again, repeating 8 times.

As the number of hidden units increases, the difference $\left(\sigma_{v}\right)$ between predicted values and experimental values decreases monotonically, as shown in Fig. 3. More complex relations can be modelled with a larger number of hidden units. However, the function may then be overfitted, as shown in Fig. 4, because experimental data always contain errors. In order to reduce overfitting, the test error (the value of the error. function for a non-trained data set) was measured, using 942 randomly chosen rows of data which were not included in the training set. Figure 5 shows the change in the test error as a function of the number of hidden units. There is a minimum at 17 hidden units. The increase in the test 


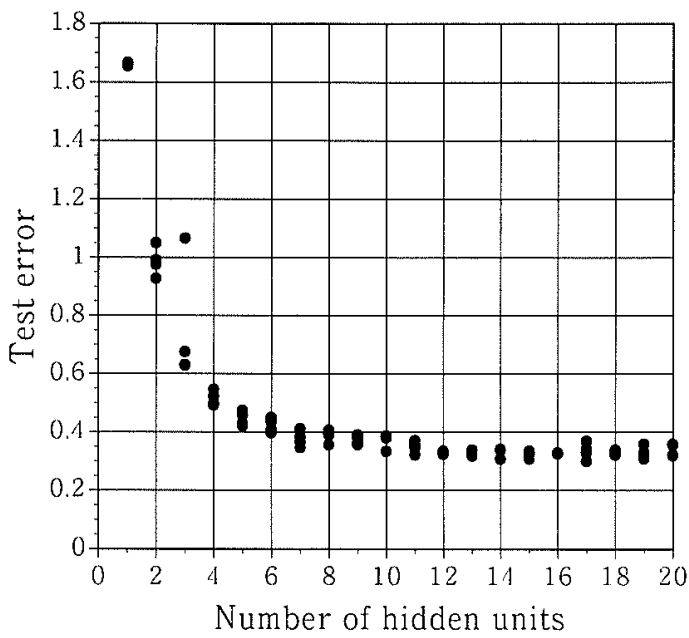

Fig. 5. Variation of test error as a function of number of hidden units.

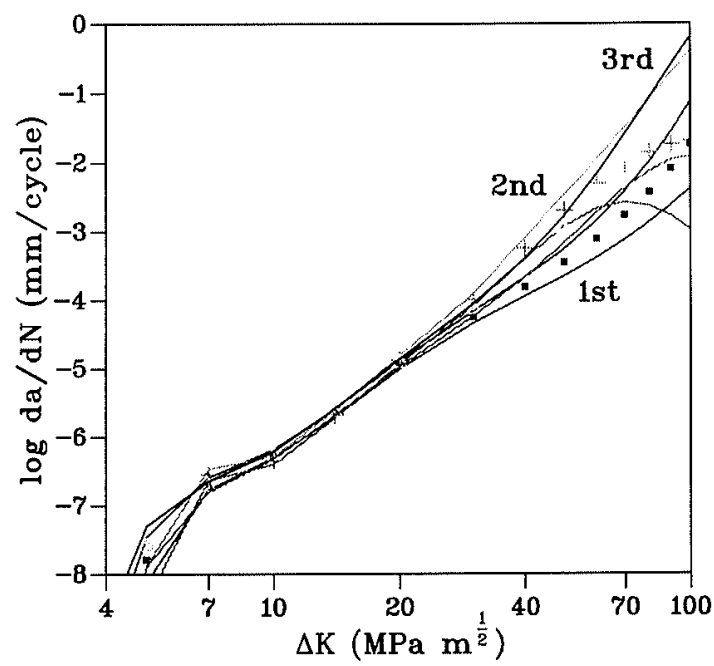

Fig. 6. Comparison of best, second best and third best model.

error over 17 hidden units indicates that the function may be overfitted. However, the increase is very small. This indicates that the distribution of data is close to the assumed Gaussian distribution and Bayesian modelling worked well. In principle, when the Bayesian modelling is completely optimized, and infinite number of hidden units could be used without overfitting. ${ }^{43)}$

\section{Committee Model}

The same data can be modelled in many ways, for example by varying the number of hidden units or starting value of $\sigma_{w}$. The variety of models thus produced can be ranked according to the magnitude of the test error. The best individual model would then have the minimum test error. However, it is possible in principle to reduce the test error further by using the average of predictions from a number of models, i.e. a committee of models.

The test errors of the variety of models produced are not very different from that of the best model, as can be seen in Fig. 5. This indicates that these models should lead to similar predictions. However, for some choices of input variables the predictions are nevertheless different because of the limitations in the training data. Figure 6 shows the predictions using the three best models for Astroloy at room temperature (The main

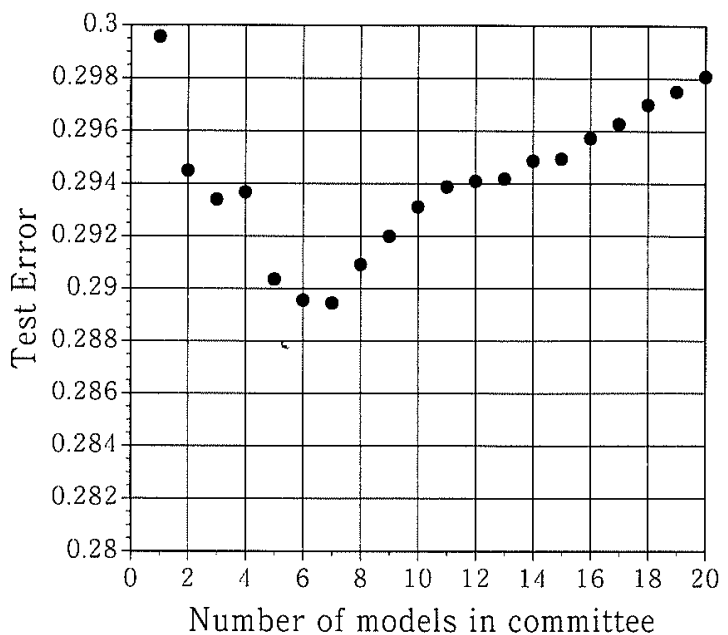

Fig. 7. Change in test error with the number of models in the committee.

experimental conditions ${ }^{13,14)}$ are summarized in the first column in Table 2.). When $\Delta K$ is less than $40 \mathrm{MPa}$ $\mathrm{m}^{1 / 2}$, the difference in the predictions is very small, but when $\Delta K$ is more than $40 \mathrm{MPa} \mathrm{m}^{1 / 2}$, the difference is large. In the latter region, the error bars are also large, indicating that there are insufficient or imprecise data in that region of input space. The error bars in this case are for $67 \%$ confidence.

A 'committee' model was therefore introduced in order to see whether more reliable predictions to be made. The method is as follows:

(1) The individual models are first ranked via their test errors.

(2) A committee of $N$ models is then formed by combining the best $N$ models, where $N=1,2,3 \cdots$.

The mean prediction $\bar{y}$ of the committee is

$$
\bar{y}=\frac{1}{N} \sum_{i=1}^{N} y_{i}
$$

and the associated error in $\bar{y}$ is given by

$$
\sigma^{2}=\frac{1}{N} \sum_{i=1}^{N} \sigma_{i}^{2}+\frac{1}{N} \sum_{i=1}^{N}\left(y_{i}-\bar{y}\right)^{2}
$$

Figure 7 shows the decrease in test error by combining models. A committee of seven of the best individual models has a minimum test error. This committee therefore was used to make a number of predictions, as shown later. Using the committee model, the agreement between experimental data and prediction is very high for both the training and test data, as can be seen in Fig. 8.

\section{Significance of Individual Inputs}

The neural network model allows us to estimate the significance of individual factors in influencing the fatigue crack growth rate using the value of $\sigma_{w}$. A high value of $\sigma_{w}$ implies that the input parameter concerned explains a relatively large amount of the variation in fatigue crack growth rate in the data set. Note that it is not an indication of the sensitivity of fatigue crack growth rate for that input parameter.

Figure 9 shows the values of $\sigma_{w}$ of the seven best 

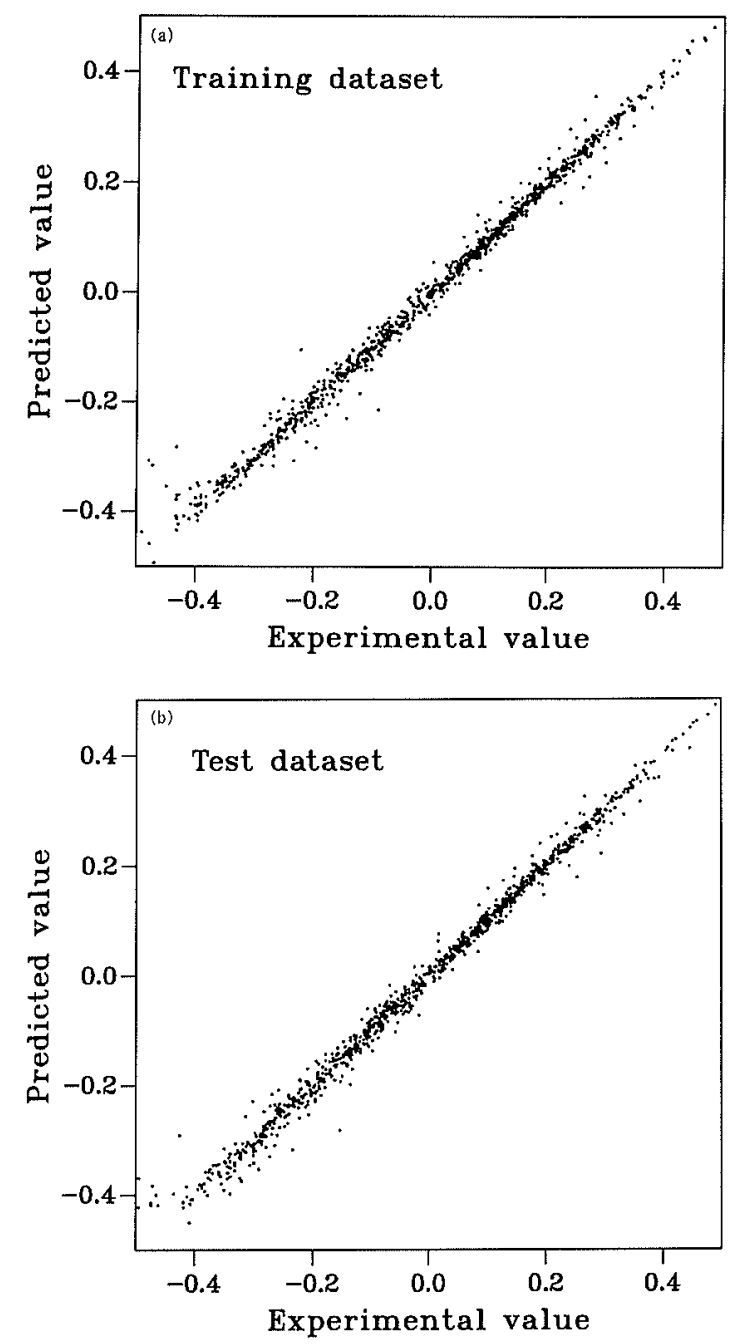

Fig. 8. Comparison between predicted and experimental fatigue crack growth rate.

(a) training data set (b) test data set models. Although some scatter is observed, some strong tendencies are found. For example, it can be found that $\log \Delta K$ is clearly more strongly linked to fatigue crack growth rate than $\Delta K$ on its own. This is coincident with the Paris' law. ${ }^{44)}$ As expected, the fatigue crack growth rate was found to be sensitive to the frequency, loading time, atmosphere and yield strength.

\section{Effect of Individual Inputs}

The neural network permits the effect of each input to be examined individually, which may be impossible to do in practice. Figure $\mathbf{1 0}$ shows the estimated fatigue crack growth rate of Astroloy at room temperature; the experimental data are from the published literature, ${ }^{13,14}$ ) summarized in Table 2. The error bar is for $67 \%$ confidence the same as before. As expected, ${ }^{15)}$ the crack growth rate decreases when the grain size increases, since that generally leads to more heterogeneous slip. ${ }^{45)}$ As a reference, although the fatigue crack growth rate seems constant near the threshold region of the $40-50 \mu \mathrm{m}$ grain alloy because of the error bar, the most probable value of the prediction substantially decreases around the region when the $\Delta K$ is reduced.

In practice, changes in the grain size are usually achieved by heat treatment. This was the case for the experimental data shown in Fig. 10. Of course, heat treatment may affect other features within the material. In fact, in addition to increasing grain size, the heat treatment $^{13,14)}$ reduced yield strength from 1021 to $954 \mathrm{MPa}$. In the neural network model, the grain size alone can be changed, as shown in Fig. 11, without altering any of the other inputs. Figure 11 is in this respect proof that an increase in grain size causes a reduction in the fatigue crack growth rate.

In fact, the crack growth rate increases when only the

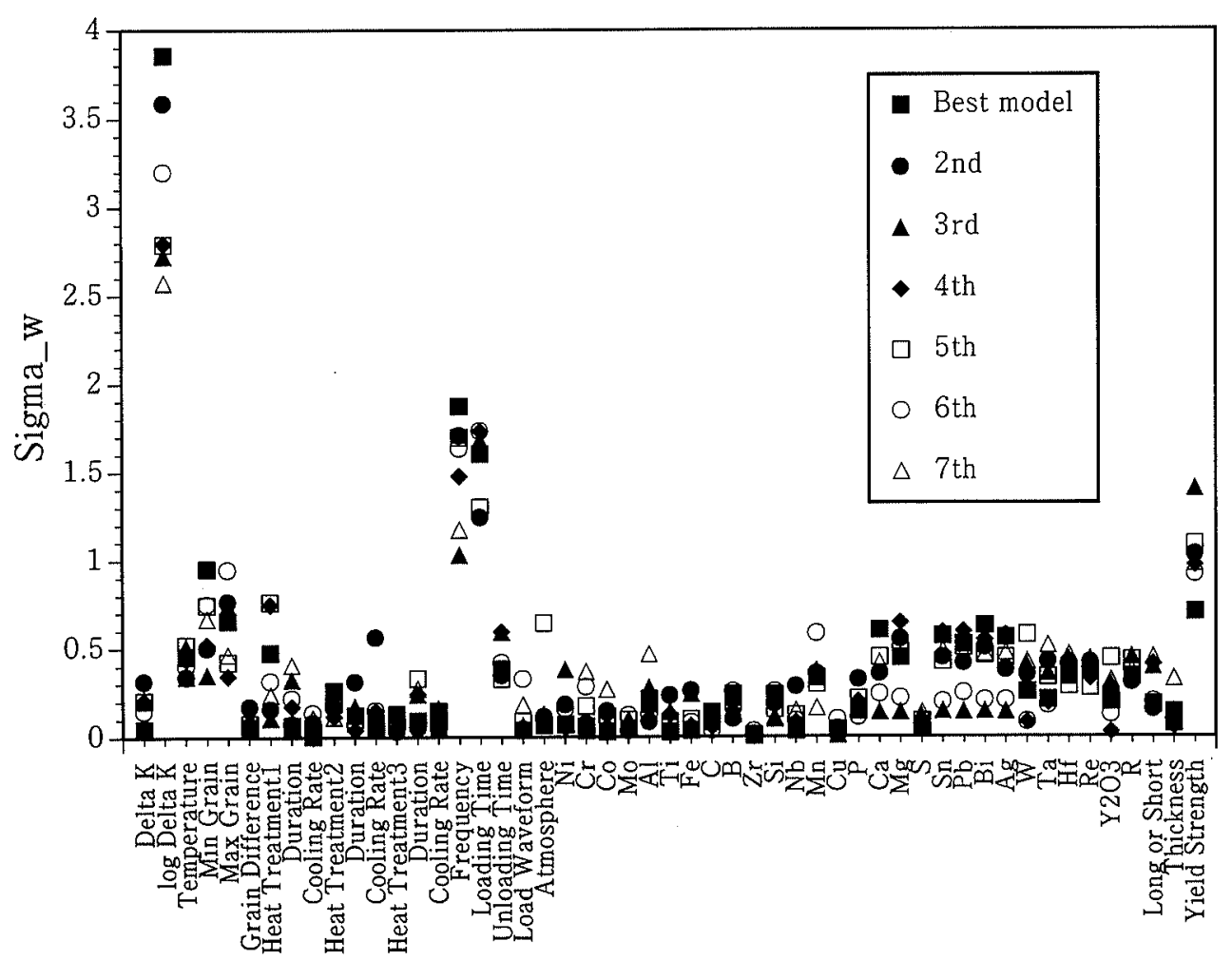

Fig. 9. Significance of individual factors on fatigue crack growth rate. 
Table 2. Main experimental condition inputted for the prediction of Fig. 10.

\begin{tabular}{c|c|c}
\hline Grain size & $11-13 \mu \mathrm{m}$ & $40-50 \mu \mathrm{m}$ \\
\hline 1st step heat treatment & $1377 \mathrm{~K}, 4 \mathrm{~h}, \mathrm{AC}$ & $1423 \mathrm{~K}, 4 \mathrm{~h}, \mathrm{AC}$ \\
\hline 2nd & $923 \mathrm{~K}, 24 \mathrm{~h}, \mathrm{AC}$ & $923 \mathrm{~K}, 24 \mathrm{~h}, \mathrm{AC}$ \\
\hline 3rd & $1033 \mathrm{~K}, 8 \mathrm{~h}, \mathrm{AC}$ & $1033 \mathrm{~K}, 8 \mathrm{~h}, \mathrm{AC}$ \\
\hline Temperature & $293 \mathrm{~K}$ & $293 \mathrm{~K}$ \\
\hline Atmosphere & Air & Air \\
\hline R-ratio & 0.1 & 0.1 \\
\hline Frequency & $40 \mathrm{~Hz}$ & $40 \mathrm{~Hz}$ \\
\hline Yield stress & $1021 \mathrm{MPa}$ & $954 \mathrm{MPa}$ \\
\hline
\end{tabular}

AC: air cooling

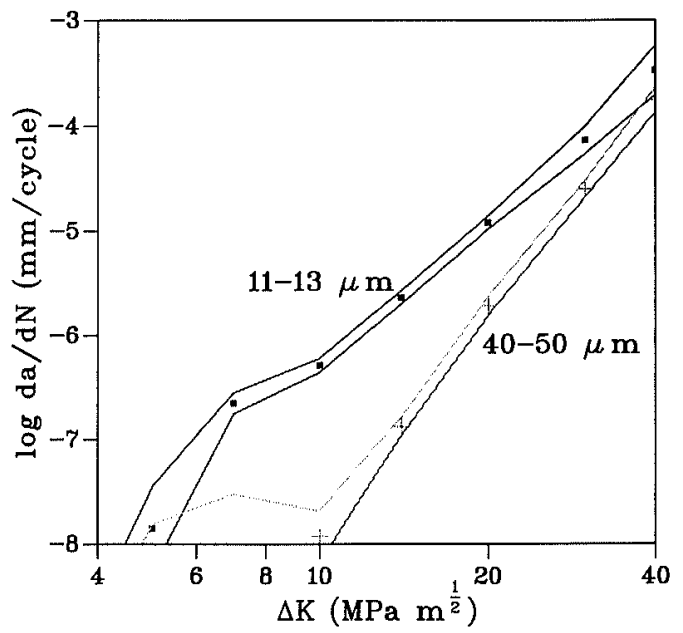

Fig. 10. Effect of grain size on fatigue crack growth rate in Astroloy.

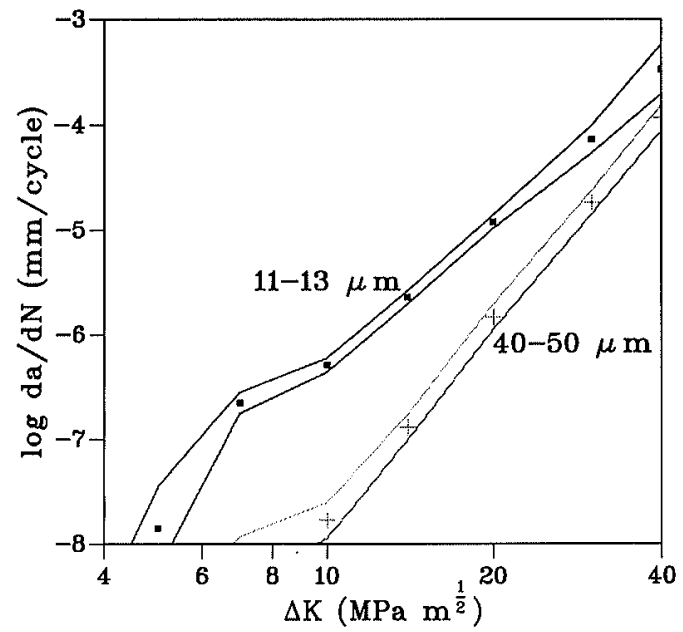

Fig. 11. Effect of grain size alone on fatigue crack growth rate in Astroloy.

value the yield strength is changed from 1021 to $954 \mathrm{MPa}$ (Fig. 12). In the Paris regime, it is considered that fatigue behaviour is dependent on crack-tip strain range, or the range of crack opening displacement $\Delta d$ per cycle. ${ }^{46)}$

$$
\Delta d=Q \frac{\Delta K^{2}}{\sigma_{\mathrm{cy}} E}
$$

where $Q$ is constant and $\sigma_{\mathrm{cy}}$ should be the cyclic yield stress (though, monotonic $\sigma_{y}$ is often used as an approximation). ${ }^{3)}$ Accordingly

$$
\frac{d a}{d N} \propto Q \frac{\Delta K^{2}}{\sigma_{\mathrm{cy}} E} \text {. }
$$

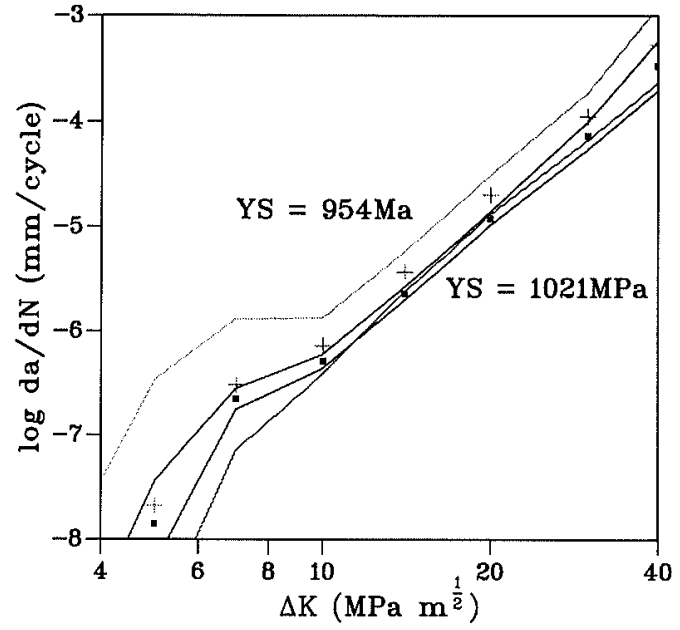

Fig. 12. Effect of yield strength alone on fatigue crack growth rate in Astroloy.

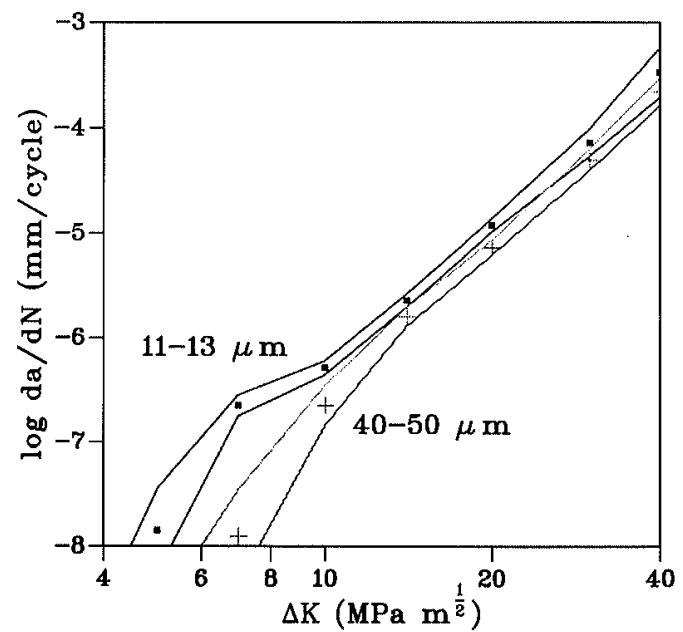

Fig. 13. Effect of heat treatment alone on fatigue crack growth rate in Astroloy.

Thus, when the yield strength is reduced, the fatigue crack growth should increase. This relation indicates that the effect of yield strength alone, shown in Fig. 12, is reasonably predicted.

The case where only the heat treatment is changed without altering the grain size or yield strength is illustrated in Fig. 13. Thus, any changes in the crack growth should indicate the presence of other factors affecting fatigue crack growth. There is a clear change in the near-threshold region which is the part most sensitive to microstructure.

The effect shown in Fig. 13 might therefore be due to the higher solution treatment reducing coarse $\gamma^{\prime}$ particles which tend to concentrate stress. ${ }^{13)}$ Our model does not include direct microstructure because such data have not been reported frequently. This would be a good area for future work.

\section{Other Predictions}

Figure 14 shows the rate of the short-crack growth. It can be seen that the slope of the curve of short-crack growth is very small and the short-crack growth rate is much higher than the long-crack growth when $\Delta K$ is small. ${ }^{47)}$ These predictions are also in accordance with our experience. 


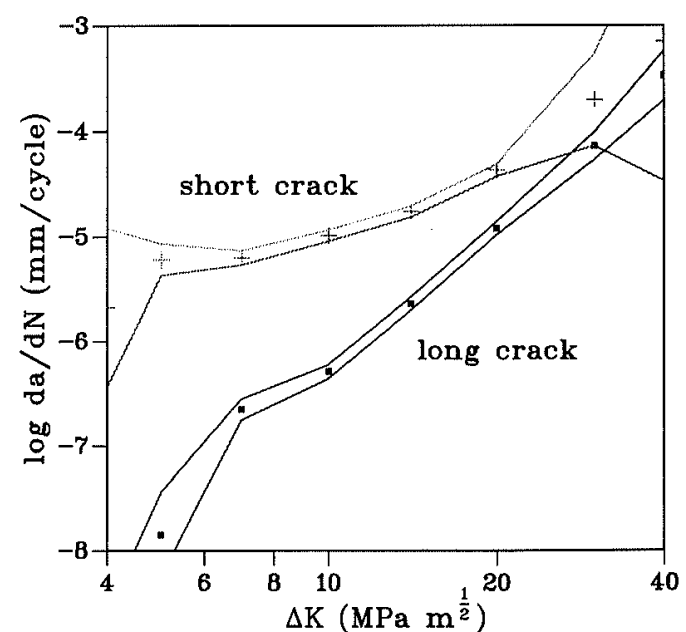

Fig. 14. Prediction of short crack growth rate in Astroloy.

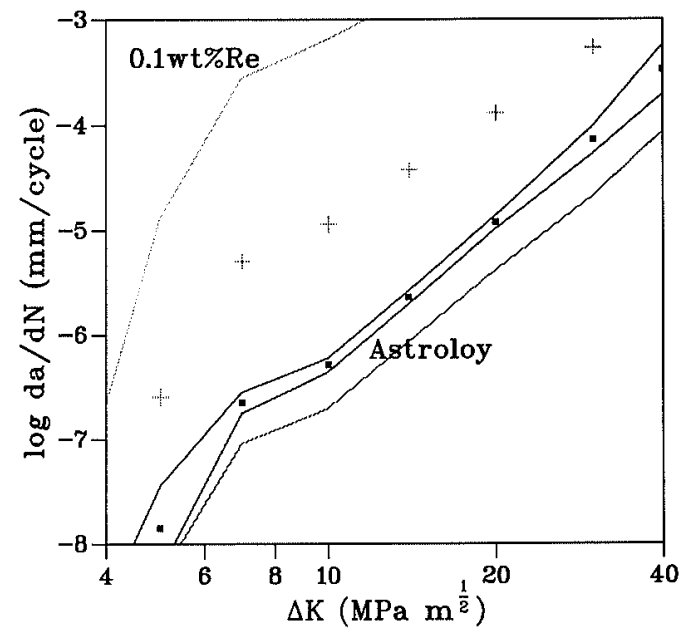

Fig. 15. Prediction of effect of addition of $0.1 \mathrm{wt} \% \mathrm{Re}$

One can also predict the fatigue crack rate under unusual conditions. The effect of adding $0.1 \mathrm{wt} \%$ to $\operatorname{Re}$ is illustrated in Fig. 15. Since the error bars are large because of the absence of experimental data, it cannot be concluded that Re really affects fatigue crack growth. This is a good example of the safety of the predictions made by the model, in that the error bars are large when the model is uncertain.

Using our model, the fatigue crack growth rate for many kinds of superalloy can be predicted. For example, Figs. 16-18 show the results for CMSX-4 and Inconel 718 , respectively. Figure 16 shows the effect of temperature in CMSX-4. The main experimental conditions inputs are frequency: $10 \mathrm{~Hz}$; load shape: sinusoidal; atmosphere: air; $R$-ratio: 0.1 ; single crystal and conventional heat treatment values. ${ }^{19)}$ When the temperature is raised, the fatigue crack growth increases. The fatigue crack growth is determined by the cyclic-plastic deformation at the crack tip. Plastic deformation has a strong temperature dependency; the higher the temperature, the easier the plastic deformation. Accordingly, it is reasonable that fatigue crack growth is easier and the growth rate faster at a higher temperature. ${ }^{48)}$

Figures 17 and 18 show the effect of addition of $\mathrm{Al}$ and $\mathrm{Nb}$. The main experimental inputs are temperature: $923 \mathrm{~K}$, grain size: $30 \mathrm{~mm}$; conventional heat treatment; frequency: $20 \mathrm{~Hz}$; atmosphere: air; $R$-ratio:

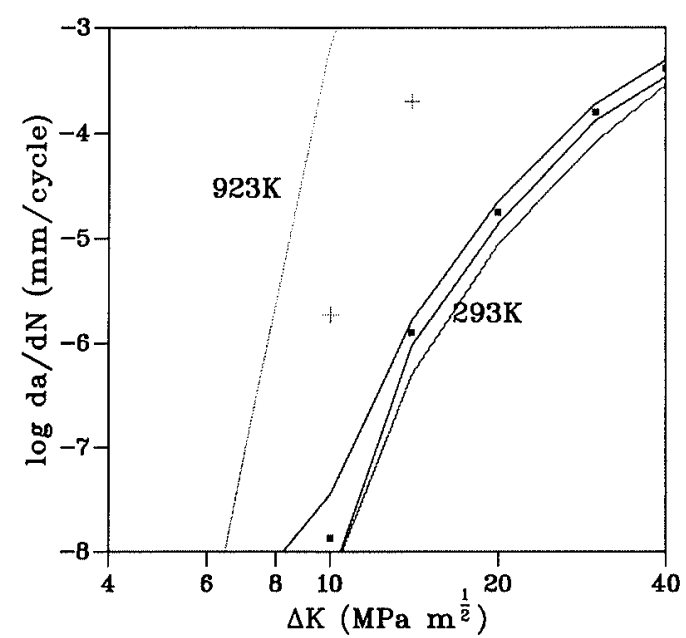

Fig. 16. Temperature dependence of fatigue crack growth rate in CMSX-4.

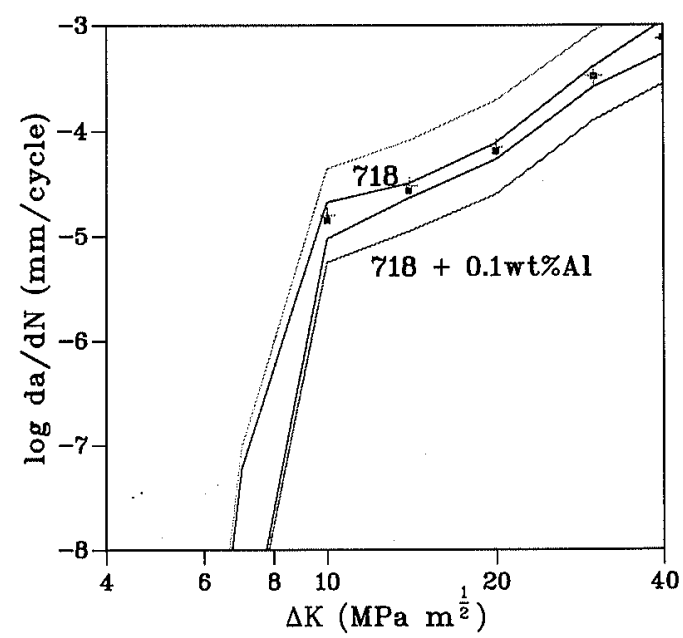

Fig. 17. Effect of addition of $0.1 \mathrm{wt} \% \mathrm{Al}$ to Inconel 718 on fatigue crack growth.

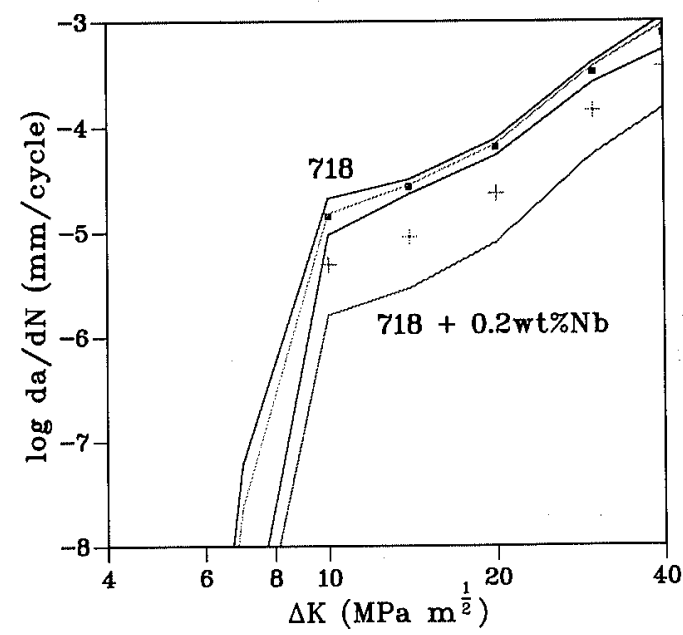

Fig. 18. Effect of addition of $0.2 \mathrm{wt} \% \mathrm{Nb}$ to Inconel 718 on fatigue crack growth.

$0.1 .^{21,22)}$ Inconel 718 is $\gamma^{\prime \prime}$ strengthened material. ${ }^{49)}$ It is also known that after ageing this alloy contains a small amount of spherical $\gamma^{\prime} .^{50)} \mathrm{Nb}$ is known to increase the $\gamma^{\prime \prime}$ phase and $\mathrm{Al}$ increases $\gamma^{\prime}$. As shown in these figures, $\mathrm{Nb}$ slightly tends to decrease the fatigue crack growth rate, though Al does not have an significant effect. However, at this time, it was assumed that the yield 
strength was constant even after the addition of these elements because appropriate data were unavailable. If the yield strength increases due to the addition of alloying elements, the fatigue crack growth would decrease, as mentioned before.

\section{Conclusion}

(1) A neural network in a Bayesian framework was found to be an effective method of estimating the fatigue crack growth rate of a large variety of nickel base superalloys. A committee of models is found to give greater reliability than the best individual model.

(2) The use of a committee appeared to reduce the test error by about $3 \%$ compared with the best individual network. Also, the error bars on the commiittee's predictions are expected to be more reliable.

(3) The model can be used to examine the effect of each variable in isolation. As a result, it was confirmed that $\log \Delta K$ is more strongly linked to the fatigue crack growth rate than to $\Delta K$, as expected from the Paris law.

(4) Similarly, it was possible to determine the effect of grain size alone. It is confirmed that an increase in the grain size should lead to a decrease in the fatigue crack growth rate.

(5) Using the neural network, it was possible to reveal the effect of heat treatment alone on the crack growth rate in the near-threshold regime, which is sensitive to microstructure. This demonstrates the ability of this method to reveal new phenomena in cases where experiments cannot be designed to study each variable in isolation.

\section{Acknowledgements}

The authors wish to acknowledge the financial support of the Engineering and Physical Sciences Research Council and of Rolls-Royce plc. They would like to thank Professor C. J. Humphreys for the provision of research facilities.

\section{REFERENCES}

1) G. W. Meetham: Metall. Mater. Technol., 14 (1982), 387.

2) T. Nicholas and J. M. Larsen: Fatigue: Environment and Temperature Effects, ed. by J. J. Burke and V. Weisss, 27th Sagamore Army Mater. Res. Conf., Plenum Press, New York, (1980), 353.

3) J. E. King: Mater. Sci. Technol., 3 (1987), 750.

4) D. J. C. MacKay: Network: Computation in Neural Systems, 6 (1995), 469.

5) D. J. C. MacKay: Neural Computation, 4 (1992), 415.

6) J. E. King, R. A. Venables and M. A. Hicks: 6th Int. Conf. on Fracture (ICF6), ed. by S. R. Valluri, D. M. R. Taplin, P. Rama Rao, J. F. Knott and R. Dubeys, NewDehli, India, (1984), 2081.

7) L. Grabowski and J. E. King: Fatigue Fract. Eng. Mater. Struct., 15 (1992), 595

8) M. R. Winstone, K. M. Nikbin and G. A. Webster: J. Mater. Sci., 20 (1985), 2471.

9) J. L. Yuen and P. Roy: Scr. Metall., 19 (1985), 17.

10) S. P. Lynch, T. C. Radtke, B. J. Wicks and R. T. Byrnes: Fatigue Fract. Eng. Mater. Struct., 17 (1994), 313.

11) H. Ghonem and D. Zheng: Mater. Sci. Eng., A150 (1992), 151.

12) M. Clavel and A. Pineau: Metall. Trans. A, 9A (1978), 471.

13) J. E. King: Met. Sci., 16 (1982), 345.

14) C. W. Brown, J. E. King and M. A. Hicks: Met. Sci., 18 (1984),
374.

15) J. Gayda and V. Miner: Metall. Trans., 14A (1983), 2301.

16) F. Gabrielli, M. Marchionni and G. Onofrio: Advance in Fracture Research, Vol. 2, ed. by K. Salama, K. Ravi-Chandar, D. M. R. Taplin and P. Rama Raos, Pergamon Press, Houston, Texas, (1989), 1149

17) J. L. Yuen, P. Roy and W. D. Nix: Metall. Trans. A, 15A (1984), 1769.

18) K. Sadananda and P. Shahinian: J. Eng. Mater. Tech., 100 (1978), 381 .

19) A. Sengupta and S. K. Putatunda: Scr. Metall. Mater., 31 (1994), 1163.

20) K. Sadananda and P. Shahinian: Met. Tech., (1982), 18.

21) M. Clavel and A. Pineau: Metall. Trans., 9A (1978), 471.

22) M. Clavel, C. Levaillant and A. Pineau: Creep-Fatigue-Environment-Interactions, (1980), 24.

23) F. Gabrielli and R. M. Pelloux: Metall. Trans. A, 13A (1982), 1083.

24) F. Gabrielli, G. Vimercati and V. Lupinc: Environmental Effects on High Temperature Fatigue Crack Growth Behaviour of Nickel Base Superalloys, Mechanical Behavior of Materials-V, Pargamon Press, China, (1987)

25) P. Shahinian: Met. Tech., 5 (1978), 372.

26) K. Sadananda and P. Shahinian: Eng. Fract. Mech., 11 (1979), 73.

27) K. Sadananda and P. Shahinian: J. Mater. Sci., 13 (1978), 2347.

28) K. Sadananda and P. Shahinian: Creep-Fatigue-Environment Interactions, ed. by R. M. Pelloux and N. S. Stoloffs, Metal Soc. of AIME, Milwaukee, Wisconsin, (1980), 86.

29) S. P. Lynch, T. C. Radtke, B. J. Wicks and R. T. Byrnes: Fatigue Fract. Eng. Mater. Struct., 17 (1994), 297.

30) J. S. Crompton and J. W. Martin: Metall. Trans. A, 15A (1984), 1711 .

31) L. A. James and W. J. Mills: Eng. Fract. Mech., 5 (1985), 797.

32) R. A. Venables, M. A. Hicks and J. E. King: Proc. Int. Symp. on Fatigue Crack Growth Threshold Concepts, ed. by D. Davidsons, AIME, (1983), 341.

33) R. A. Venables and J. E. King: Fatigue 84, (1984), 1371.

34) M. A. Hicks and J. A. King: Int. J. Fatigue, 5 (1983), 67.

35) J. L. Yuen, C. G. Schmidt and P. Roy: Fatigue Fract. Eng. Mater. Struct., 8 (1985), 65.

36) J. C. Healy, L. Grabowski and C. J. Beevers: Fatigue Fract. Eng. Mater. Struct., 15 (1992), 309.

37) B. A. Cowles, D. L. Sims, J. R. Warren and R. V. Miner, Jr.: Trans. ASME, 102 (1980), 356.

38) B. Lawless, S. D. Antolovich, C. Bathias and B. Boursier: Fracture: Interaction of Microstructure, Mechanisms and Mechanics, ed. by J. M. Wells and J. D. Landess, Metall. Soc. AIME, Los Angels, California, (1984), 285.

39) H. P. Degischer, W. Hein, H. Strecker, W. Wagner and R. P. Wahi: Z. Metallkd., 78 (1987), 237.

40) W. H. Press, S. A. Teukolsky, W. T. Vetterling and B. P. Flannery: Numerical Recipes in C, 2nd Ed., Cambridge University Press, 418.

41) D. E. Rumelhart, G. E. Hinton and R. J. Williams: Nature, 323 (1986), 533.

42) D. J. C. MacKay: Neural Computation, 4 (1992), 448.

43) R. M. Neal: Radford Thesis 'Bayesian Learning for Neural Networks', Dept. of Computer Science, Univ. of Toronto, (1995).

44) P. C. Paris and F. E. Erdogan: J. Basic Eng. (Trans. ASME, D), 85 (1963), 528

45) B. A. Lerch, Jayaraman: Mater. Sci. Eng., 66 (1984), 151.

46) J. F. Knott: Fundamental Mechanics, Butterworths, London, (1973), 240.

47) S. Suresh and R. O. Ritchie: Int. Met. Rev., 6 (1984), 445.

48) M. Klesnil and P. Lukás: Fatigue of Metallic Materials, Elsevier, Czechoslovakia, (1980), 130.

49) D. F. Paulonis, J. M. Oblak and D. S. Duvall: Trans. Am. Soc. Met., 62 (1969), 611.

50) R. Cozar and A. Pineau: Metall. Trans., 4A (1973), 47.

\section{Appendix}

Values of coefficient (weight) and bias of the functions 
of the best one model (17 hidden units). Equations (1), (2) and these values allow us to make prediction of fatigue crack growth. The data arranged in a continuous horizontal sequence in the following order:

$$
\begin{aligned}
& \theta_{1}^{(1)}, w_{1,1}^{(1)} \cdots w_{1,51}^{(1)}, \\
& \vdots \\
& \theta_{17}^{(1)}, w_{17,1}^{(1)} \cdots w_{17,51}^{(1)}, \\
& \theta^{(2)}, w_{1}^{(2)} \cdots w_{17}^{(2)},
\end{aligned}
$$

\begin{tabular}{|c|c|c|c|c|c|c|c|}
\hline-1.41962 & -0.0161546 & 4.12123 & 0.257802 & -1.84335 & 1022 & 0.0104604 & -0.797241 \\
\hline-0.0179489 & -0.0004677 & -0.0859964 & 0.111289 & 0.01 .34014 & (1).(34) 5729 & 0.0128502 & $-(0.1 .37901$ \\
\hline 0.487949 & 0.968457 & 0.32747 & -0.01448 .5 & -0.0135372 & 10.1175204 & 0.00772629 & $-0.0(1) 0.3421$ \\
\hline-0.0237001 & 0.00211448 & 0.00524809 & 0.00377307 & -0.0622692 & 6.0303017 & -0.0006022 & 0.153973 \\
\hline 0.001$) 1982$ & -0.263953 & -0.0038223 & -0.0244352 & -0.61717 & -0.335839 & 0.0205018 & -0.552686 \\
\hline-0.467561 & -0.675345 & -0.539403 & -0.210871 & -0.12059 & .0 .2306 .55 & -0.291287 & 0.0785794 \\
\hline 0.212356 & -0.131145 & -0.0115359 & -0.718597 & & & & \\
\hline 0.585487 & 0.00250017 & 5.66266 & -0.152835 & -0.407749 & -() 207247 & $-(0.0) 402341$ & 0.241687 \\
\hline 0.0155749 & -0.001802 & -0.0561856 & -0.0629048 & 0.0327606 & 0.198522 & -0.052055 & 0.1634 \\
\hline 1.06604 & -1.65668 & -0.109145 & 0.0108458 & 0.0460059 & -81.101995414 & 010237171 & 0.01230147 \\
\hline 0.0266368 & 0.0445047 & 0.00678326 & -0.0151224 & -0.0002333 & $-(0.02287507$ & 0.0012744 & $-(0.11 .5491$ \\
\hline-0.0046314 & 0.251529 & 0.0109234 & 0.0122164 & -0.0107938 & 0.001082641 & 0.00534393 & -0.00188049 \\
\hline-0.0058925 & -0.0127843 & -0.0084024 & 0.0268314 & -0.0345232 & -0.140817 & .0 .180683 & 0.083164 .5 \\
\hline-0.295983 & -0.26804 & 0.00624231 & 0.814157 & & & & \\
\hline 0.819681 & -0.0198176 & -0.0308398 & -0.552437 & 0.0329082 & 0.19933 & -0.0115338 & 0.00814642 \\
\hline 0.00451352 & -0.0009641 & 0.0987821 & -0.150189 & 0.0330407 & -0.0524076 & -0.0504001 & 0.0922511 \\
\hline 4.31651 & -0.481592 & -0.636487 & -0.0139726 & 0.011738 & -0.14403776 & -0.0061504 & 0.00716756 \\
\hline-0.0282924 & 0.0884676 & -0.0089834 & 0.00937136 & $0.16627 ?$ & .0 .0805361 & -0.0005913 & -0.483786 \\
\hline-0.0098449 & -0.257618 & 0.00931197 & -0.100328 & -0.229807 & -0.108105 & -0.0151873 & $-0.1991+2$ \\
\hline-0.159894 & -0.257499 & -0.192879 & 0.186388 & 0.0645236 & 0.14961913 & 0.0907889 & 0.0642072 \\
\hline 0.155679 & 0.0390409 & -0.240381 & -0.852896 & & & & \\
\hline 0.561134 & -0.0032272 & 4.00978 & -0.0275688 & -0.0242349 & $\mid 0.37889)$ & 0.073556 & $-0.78+581$ \\
\hline 0.0195447 & -0.00072 & 0.0446812 & 0.0456867 & -0.0318523 & $(0.101626$ & 0.00209257 & $-0.088+6638$ \\
\hline 2.03949 & -1.54607 & 0.247631 & -0.0178264 & 0.0841 .59 & 0.111 .582748 & 0.0131925 & $0.19188 ! 65$ \\
\hline-0.0183567 & 0.05867 & 0.00702303 & $-0.00400 \leq 2$ & 0.106231 & $-(1.68918 .53$ & -0.0008272 & $-0: 96957$ \\
\hline-0.024051 & 0.274113 & 0.00402062 & -0.04826 .37 & $-0.17157 ?$ & -co.18594047 & -0.0292625 & -01.15246 \\
\hline-0.12721 & -0.18879 & -0.148521 & -0.0026538 & 0.0129257 & 011217895 & 0.024689 .5 & $-0.021 ! 69444$ \\
\hline 0.194307 & 0.143173 & 0.0372302 & 0.582946 & & & & \\
\hline-0.449032 & 0.0109593 & -5.26169 & -0.0495304 & $0.2226 !$ & 11.213447 & -0.0255162 & -0.127719 \\
\hline .0 .0295733 & -0.0011472 & 0.0499055 & 0.0373259 & 0.027784 .3 & 0.01319074 & -0.0019823 & $-(0.6137017$ \\
\hline-1.0579 & 2.11413 & -0.0667491 & 0.0222251 & -0.0006113 & 0.1126670 .5 & 0.00498569 & $-0.1 ; 180014$ \\
\hline-0.0161592 & -0.141771 & -0.0002717 & -0.0013464 & 0.00388176 & $-(1.140566$ & $-(0.0017689$ & 0.013 .6808 \\
\hline 0.00116966 & 0.242466 & 0.0109801 & $-1) .0361813$ & 0.117476 & -0.11694675 & $-0,008.5058$ & $-(1,4118083$ \\
\hline-0.0950246 & -0.125897 & -0.106115 & -0.0177107 & 0.00646936 & $.0 .11 ! 86503$ & -0.0060164 & 0.157961 \\
\hline 0.443351 & 0.0981107 & 0.0784435 & 0.103548 & & & & \\
\hline-0.02 .18043 & $Q Q 150633$ & -0.608918 & -0.737738 & 0.202655 & $-(1.406489$ & -1.0116217 & -0.163579 \\
\hline 0.0141651 & 0.000176 .27 & 0.0650056 & 0.059171 .5 & .0 .0476826 & $-(1) .103665$ & -0.015878 & (). $2.27+0: 4$ \\
\hline-1.0734 & 3.68006 & 0.0892576 & -0.0093181 & 0.0918879 & 0.0156584 & 0.00073617 & 0.004 .23107 \\
\hline-0.0006725 & -0.139716 & 0.00467952 & -0.0062118 & -0.0115122 & $(1.10926472$ & 0.00033128 & 0.135521 \\
\hline$-0.003864 i$ & -0.248675 & -0.0157045 & 0.0120913 & -0.253276 & -19.143195 & 0.024238 & -0.227617 \\
\hline-0.193538 & -0.276131 & -0.222298 & -0.0618 .526 & -0.0373866 & $-0,0301589$ & -0.0314462 & $-0.0-503688$ \\
\hline 0.246311 & 0.014686 & -0.0324843 & 0.0914715 & & & & \\
\hline 0.438924 & 0.0227281 & -1.02684 & -0.09855378 & 0.00277838 & 1). 298935 & .11 .0056329 & -0.784714 \\
\hline 0.0115347 & 0.00059105 & 0.0766978 & 0.0506002 & 0.0419074 & .901012 & 0.063258 & $-(1) 21 \div 562$ \\
\hline 0.245011 & 1.30115 & -0.20007 & 0.0370475 & -0.022231 .5 & $\left(4015356^{\circ}\right)$ & 11.0576677 & $.0 .194,59763$ \\
\hline 0.0008818 & 0.0521372 & -0.0025942 & -0.0072765 & -0.158215 & .0161742625 & -11.0006835 & 0.0118478 \\
\hline 0.0108923 & 0.14826 & -0.003159 & -0.0908588 & $-0.20(1001$ & $-1: 106883$ & $.0 .02+2451$ & -10.131147 \\
\hline-0.15614 & -0.216724 & .0 .177241 & -0.0270045 & 0.028 .3855 & 11152622 & 0.1768 .32 & -(1) isibu2 \\
\hline 0.32098 & 0.0120692 & 0.0897762 & 0.469998 & & & & \\
\hline 1.30187 & .0 .0084515 & 3.5945 & 0.320672 & 0.805743 & 1154573 &.$(1,010108296$ & $-0.21746,3$ \\
\hline$-0.0091 \div 02$ & 0.00051102 & 0.33248 & $0.04024 !$ & .0 .008246 .5 & $(6.616) 1962$ & $0017(0223$ & -0.1209254 \\
\hline 0.257193 & -0.206896 & -0.324894 & 0.00065957 & 0.0614114 & Joius6680.4 & i). 0373182 & 0.00326118 \\
\hline 0.00367172 & - & -0.0056234 & -0.0052304 & -0.056 .3461 & $-i 1.345112$ & $-6.78 \mathrm{E}-05$ & 0.355751 \\
\hline 0.00986222 & 0.132207 & -0.0019856 & -0.110205 & -0.103319 & -0.0762208 & -0.0172481 & -0.046 .3594 \\
\hline-0.0877709 & -0.109786 & -0.0949689 & -0.148702 & -0.0677838 & 0.11114475 & 0.00935145 & $-(0.1859 .51$ \\
\hline-0.253274 & -0.171996 & 0.0592553 & -0.41006 & & & & \\
\hline-0.549812 & -0.0290427 & -0.289947 & 0.531306 & 1.02075 & .01 .120868 & 0.00855005 & -0.524037 \\
\hline-0.0009301 & -0.00049 & 0.0628477 & 0.00145126 & -0.01888889 & (1).8)104217 & .0 .0891 .514 & $0.00+01017 ?$ \\
\hline 1.34823 & -1.81218 & 0.297815 & -0.034886 & -0.0573755 & $-0.1: 1215.48$ & $-(1) .0402761$ & 0.01 .890 .3 \\
\hline-0.0148272 & 0.0641172 & -0.0012181 & 0.00519207 & 0.0059096 & -10.65988227 & 000068113 & -0.155811 \\
\hline-0.0017373 & -0.582812 & 0.00065073 & 0.0407060 & 0.227746 & 01.11609 .3 & 0.0294663 & $.(1.20), 72$ \\
\hline-0.170969 & -0.249101 & -0.198705 & 0.00945777 & 0.0205774 & 0.10447502 & 0.112789 & -0.027 .4014 \\
\hline-0.00565 .44 & -0.0422177 & -0.0351079 & 0.866797 & & & & \\
\hline 1.15716 & -0.0025694 & 4.959 .33 & -0.665496 & $-(0.559449)$ & (1. $.6785: 3$ & 0.0318201 & $-0.0 .39+4 ! 24$ \\
\hline-0.0235558 & 0.0002849 & 0.143526 & 0.079450 .4 & -0.023 .5873 & $\left(0.11^{4}\right) 3.3735$ & 0.00621995 & 0.123055 \\
\hline .0 .617925 & -2.40968 & -0.348993 & 0.0153375 & 0.0168077 & 0.0229109 & - (j.0334517 & -0.00566677 \\
\hline .0 .00901 th & 0.07878 .46 & -0.001557 & -0.0037628 & 0.0159594 & $-(1.1+85.28$ & $6.48 \mathrm{E}-0.5$ & 0.0220519 \\
\hline-0.0040508 & 0.3050 .32 & -0.0020354 & 0.0508923 & -0.0742014 & $(3.1) 314115$ & 0.0029312 & -0.06 .36448 \\
\hline-0.0497287 & -0.0836333 & -0.0614629 & 0.03930 .2 & 0.0019 .40 .3 .4 & -10.1 .3025 .3 & -0.169576 & 0.0572564 \\
\hline 0.45968 & 0.0723947 & 0.019052 & -0.0226742 & & & & \\
\hline 0.137609 & 0.0040812 & 5.14098 & .0 .313331 & -0.75983 & 01216031 & 1.0200252 & $0.41)](171$ \\
\hline
\end{tabular}


ISIJ International, Vol. 36 (1996), No. 11

\begin{tabular}{|c|c|c|c|c|c|c|c|}
\hline-0.0038815 & -0.0007176 & 0.068105 & -0.0731455 & 0.0252933 & 0.11 .159879 & 0.04467 & -0.0553911 \\
\hline 1.24723 & 0.256464 & -0.241518 & 0.0228675 & -0.0577381 & 01121976 & .0 .0322817 & 0.011 .35074 \\
\hline 0.0224943 & 0.0596109 & 0.00388392 & -0.0230036 & -0.0553351 & 0.11634433 & 0.).00017498 & $-0.2+4794$ \\
\hline 0.00614841 & -0.0408179 & -0.0320709 & -0.0252618 & -0.0678636 & -0.01333569 & .1).0060419 & -0.0 .595984 \\
\hline-0.049194 & -0.0755708 & -0.0579398 & -0.0016536 & -0.0315945 & .1). 106005 & -0.133155 & 0.0664205 \\
\hline-0.07923 & 0.107823 & -0.0826431 & 0.80528 & & & & \\
\hline-0.103268 & -0.0046591 & -4.93577 & 0.064334 & 0.199896 & () 255825 & 0.0122491 & 0518244 \\
\hline-0.0180949 & -0.0011443 & 0.196136 & 0.0377392 & -0.0026402 & 0.0751392 & 0.0523123 & -0.0810566 \\
\hline-0.990539 & 0.90651 & -0.171154 & -0.0009319 & -0.0935835 & 0.0 .525959 & i. 00996061 & -0.006519 \\
\hline-0.0214085 & 0.030909 & -0.0045416 & -0.0042301 & -0.0256392 & -0.256156 & -0.0010118 & 0.188818 \\
\hline-0.0010563 & -0.160152 & 0.0129229 & 0.0658218 & 0.331348 & 0.194058 & 0.0116979 & 0.248728 \\
\hline 0.256384 & 0.36088 & 0.292048 & 0.0834913 & 0.011301 & (1.6) 82732 & 0.0154206 & 0.04 .45511 \\
\hline 0.0434354 & 0.0815188 & 0.0117528 & .1 .07729 & & & & \\
\hline 0.314774 & -0.040034 & -0.381057 & -0.897832 & -0.264672 & -294073 & 1). 0181756 & -0.322328 \\
\hline-0.0121481 & -0.0001603 & 0.0878642 & -0.116777 & .0 .0016514 & $0 .(i) 128558$ & 11.00426682 & -0.0 .546424 \\
\hline 0.34135 & 0.303801 & -0.119733 & -0.0219934 & 0.0663369 & $-0 .(1) 28603$ & 11,00513059 & $-0.012 \times 177$ \\
\hline-0.0291006 & -0.247727 & -0.0025908 & 0.0101432 & 0.191893 & .01 .107235 & 0.00025784 & -0.05866 \\
\hline .0 .00366581 & -0.0296207 & 0.00449987 & 0.0618769 & 0.147288 & 06950166 & 0.0129313 & 0.1 .33803 \\
\hline 0.117377 & 0.159999 & 0.131126 & -0.133485 & -0.090784 & -0.187052 & -0.255689 & 0.0251078 \\
\hline 0.468245 & -0.0149445 & -0.122632 & -0.932455 & & & & \\
\hline-0.962353 & 0.0120859 & -3.52892 & 0.224586 & 0.0317055 & 11.53007 & 0.0730724 & $0 .(5) 1058$. \\
\hline 0.00831608 & 0.00040014 & -0.200926 & 0.16616 & -0.0108734 & $-0 .(14) 183.56$ & .0 .0180394 & 0.01 .1798 .36 \\
\hline-2.27475 & 0.496536 & -0.111228 & 0.00753608 & 0.051493 .5 & $(1,1) 29527$ & -0.03670 .31 & $-0 .(i 1) 9852$ \\
\hline-0.012557 & -0.123928 & 0.00788101 & 0.00279065 & -0.0052975 & 141801 & 11.0009931 & $0.1 k: 1) 2326$ \\
\hline-0.0136052 & -0.229956 & 0.00624093 & -0.0207847 & 0.204217 & 1.106577 & .0.0199774 & (1.) 151062 \\
\hline 0.152024 & 0.224609 & 0.177026 & -0.111855 & -0.0302492 & $-(1.1: 1196974$ & 10.0033652 & $-(0.64 .4 \div 725$ \\
\hline-0.417461 & -0.0014194 & 0.0227719 & -0.34889 .5 & & & & \\
\hline 1.01953 & -0.008236 & 5.31535 & -0.519 .534 & 1.09478 & (1) 254321 & 0.0423326 & 0.268043 \\
\hline-0.0200316 & 0.00166211 & -0.0648407 & 0.11855 & 0.0065994 & 0.19577847 & -0.05171 & -0.125563 \\
\hline 1.9443 & -1.12325 & -0.174255 & 0.00962481 & 0.0304073 & 0.0122011 & 000176161 & $3081 \div 05$ \\
\hline-0.0041914 & -0.0860648 & -0.005617 & -0.0036149 & 0.0483951 & $0.0 \times 87323$ & -0.0016 .565 & -0.0473863 \\
\hline 0.0198439 & 0.0317458 & 0.0275842 & 0.0775849 & -0.0561639 & -0.0307539 & 0.0149039 & -0.051 .4344 \\
\hline-0.0447774 & -0.0603983 & -0.0504416 & -0.0682791 & 0.00345538 & 0.00603354 & $-1) .0147936$ & -0.118561 \\
\hline 0.274506 & 0.280638 & 0.0184508 & 0.394107 & & & & \\
\hline 0.5897 & 0.00016144 & 0.00532556 & 0.043709 & -0.201114 & $-(0.367367$ & 00159958 & -0.226898 \\
\hline-0.0311764 & 0.00098011 & -0.118534 & -0.008083 & -0.00878833 & 0.0 .513203 & 0.00604986 & -0.0799531 \\
\hline 3.53152 & -0.614506 & -0.133173 & 0.0559532 & -0.0370831 & $-0.6 ! 66272$ & -6. igl:-05 & 4.2(0):-05 \\
\hline-0.0041979 & 0.270673 & -0.0004865 & -0.004936 & -0.0133884 & 0.166184 & 0.100063617 & -0.154707 \\
\hline 0.0145388 & 0.132198 & -0.0121099 & 0.00919955 & -0.31294 .5 &.$(1) ! 54454$ & 1.00 .5129 .53 & -0.27885 .57 \\
\hline$-0,233885$ & -0.343638 & -0.271835 & 0.181 .542 & 0.02665511 & -11.100644 & .0 .11 .5583 & $0.1 \times 1892$ \\
\hline-0.223744 & 0.0147336 & 0.022098 & -0.902705 & & & & \\
\hline 1.01009 & -0.0116936 & 5.22962 & -0.509488 & 0.00086873 & 11.22 .38 & 0.0341165 & 0.027565 \\
\hline-0.0062006 & -0.0009626 & -0.0322381 & -0.062991 & 0.0538315 & .116354556 & 0.0680096 & 0.0 .348083 \\
\hline 2.24933 & -1.3997 & 0.0448716 & -0.0064356 & 0.0214896 & -0.03354093 & -0.0278161 & -0.0073881 \\
\hline-0.0136734 & -0.0919141 & -0.0071582 & 0.0125108 & -0.0368662 & -0.1212276 & 1.00013078 & -0.0388158 \\
\hline 0.00060467 & 0.30398 & -0.0107303 & 0.0319183 & -0.126684 & -0.073507 & 0.0030166 & -0.116411 \\
\hline-0.10216 & -0.13587 & -0.114262 & 0.0414296 & 0.0490387 & 0.04416036 & 0.119095 & $-(0.04) 14238$ \\
\hline 0.504224 & 0.043995 & -0.0076497 & 0.285719 & & & & \\
\hline-0.674524 & 6.82259 & 5.96923 & 8.57284 & 7.71311 & $5.3360 \%$ & -6.16183 & 5.13955 \\
\hline-7.22549 & -7.8114 & 7.22451 & 3.86769 & 6.45772 & .7 .0264 & 6.9 .3241 & $.7(01) 135$ \\
\hline-10.1016 & 5.79936 & & & & & & \\
\hline
\end{tabular}

